\title{
Tobacco use among urban slum dwellers attending a cancer screening clinic in the National Capital Region of India: a cross-sectional study
}

\author{
Suzanne T Nethan ${ }^{1}$, Dhirendra N. Sinha ${ }^{1}$, Ashwini Kedar ${ }^{2}$, Vipin Kumar ${ }^{3}$, Shashi Sharma ${ }^{4}$, Roopa Hariprasad ${ }^{5}$ and Ravi Mehrotra ${ }^{6}$ \\ ${ }^{1}$ School of Preventive Oncology, A/27, Anandpuri, West Boring Canal Road, Patna 800001, India \\ ${ }^{2}$ National Viral Hepatitis Control Program, Ministry of Health \& Family Welfare, Nirman Bhawan, Near Udyog Bhawan Metro Station, Maulana Azad Rd, Delhi \\ 110011, India \\ ${ }^{3}$ Nippon Data System Ltd., B-14, Sector 8, Noida 201301, India \\ ${ }^{4}$ Senior Biostatistician, C58/25, B902, Jagdamba Apartments, Sector 62, Noida 201307, India \\ ${ }^{5}$ Division of Clinical Oncology, Indian Council of Medical Research-National Institute of Cancer Prevention \& Research (ICMR-NICPR), I-7 Sector 39, Noida \\ 201301, India \\ ${ }^{6}$ Chief Executive Officer, ICMR - India Cancer Research Consortium, IRCS Building, Red Cross Road, Delhi 110003, India
}

\section{Abstract}

Background: Tobacco consumption in India varies based on the place of residence (urban/ rural). Minimal, exclusive information exists regarding the same for 'urban slum' dwellers. The current study determines the tobacco use pattern among such individuals in Noida, Uttar Pradesh (India).

Methods: A cross-sectional study was conducted among the urban slum residents visiting the institutional clinic between December 2016 and June 2019. Apart from tobacco history, routine recording of the basic demographic details and oral visual examination was carried out for the participants. For categorical data, the percentage of different parameters was calculated and for quantitative data, descriptive statistics were calculated. Chisquare or Fisher's exact tests were employed to determine the association between the two categorical variables. To find the strength of association between tobacco use and the socio-demographic factors, univariate and multivariable binary logistic regression was used.

Results: Among 2,043 urban slum respondents (602 male, 1441 female), $15.0 \%(n=308)$ currently consumed tobacco. The majority were smokeless tobacco (SLT) users (among both males and females). Among males, khaini (42.1\%) and gutkha (32.5\%) and among females gul (36.1\%) were the most widely used tobacco products.

Conclusion: The majority of the Noida urban slum population attending the screening clinic consumed SLT. Gender variation in the tobacco form and product-specific consumption patterns indicates that the undertaking of urban slums-specific surveys is essential. Tobacco control programmes must incorporate appropriate strategies addressing such subgroups of tobacco users.

Keywords: urban slums, Noida, India, tobacco, oral cancer

Correspondence to: Ravi Mehrotra Email: ravi.mehrotra@gov.in

ecancer 2021, 15:1230

https://doi.org/10.3332/ecancer.2021.1230

Published: $11 / 05 / 2021$

Received: 02/03/2021

Publication costs for this article were supported by ecancer (UK Charity number 1176307).

Copyright: $($ ) the authors; licensee ecancermedicalscience. This is an Open Access article distributed under the terms of the Creative Commons Attribution License (http:// creativecommons.org/licenses/by/3.0), which permits unrestricted use, distribution, and reproduction in any medium, provided the original work is properly cited. 


\section{Background}

Tobacco, in any form, is the primary aetiological factor for the development of oral cancer and yet the most preventable cause of death [1]. Tobacco use is also a non-communicable disease risk factor that is responsible for $70 \%$ of mortality in India [2]. A myriad variety of both smoked and smokeless tobacco (SLT) products are available in the Indian market [3]. Bidi is the most commonly smoked form (8\% adult users), while khaini is the most common smokeless form of tobacco (11\% adult users) consumed in India [4]. By 2025 , 27.2\% of the total cancer burden is predicted to comprise tobacco-related cancers [5]. India contributes to one-third of the global oral cancer burden [6].

Rapid and large-scale mobilisation of rural residents to urban areas for employment, in many low and middle-income countries, has resulted in the urbanisation of poverty. Such a phenomenon and deprivation of available services often leads to residential crowding, and social fragmentation and exclusion, referred to as a 'slum/urban slum' [7]. Urban slum dwellers have poor health indicators either due to the lack of access to affordable healthcare or due to prevailing poor sanitary conditions and lack of health education. Due to the various socio-economic issues, they are also more prone to developing addictions, such as tobacco use and other substance abuse. The 2011 census reported of 377 million residents in the urban slums of India which is predicted to rise to 535 million by 2026 [8, 9]. The estimated number of individuals living in the urban slums of Noida (Uttar Pradesh, UP) is 49,407 [10].

The previously held national surveys, such as the Global Adult Tobacco Surveys (GATS) [4] and the National Family Health Surveys (NFHS) [11], have discussed the tobacco consumption patterns among both rural and urban inhabitants of the Indian states and union territories. However, the current information regarding tobacco consumption patterns of urban slum dwellers (including those in UP, where this study was carried out) [12-23], and if they are any different or similar to consumption patterns among the other two locational groups (urban and rural) of tobacco users, is inadequate. Even the aforementioned national-level surveys have either not reported this information separately (in GATS the information is provided for urban residents in toto, not exclusively for the urban slum dwellers) [4] or only in one round (NFHS 3, 2005-06) [24].

However, there is a paucity of studies in the literature about the prevalence, pattern of tobacco use and the factors determining tobacco use among urban slum dwellers. Hence, the present study was conducted to determine the pattern of tobacco consumption among residents of urban slums in Noida (UP) attending our cancer screening clinic.

\section{Methods}

\section{Study design}

This study used the cross-sectional study design.

\section{Setting}

The study was conducted at the cancer screening clinic at our organisation in Noida, UP (India). At the clinic, regular screening of people is conducted for hypertension (HT), diabetes mellitus (DM), oral cancer and oral potentially malignant disorders (through oral visual examination), breast cancer (through clinical breast examination) and cervical cancer and pre-cancer (through Papanicolaou and visual inspection with acetic acid tests). Systematic population-based screening and opportunistic screening are conducted at the facility. People are referred from nearby facilities for screening of either breast, oral, or cervical cancer. These people were made aware of these three common cancers and were then motivated to get themselves screened.

Systematic population-based screening is carried out with the help of primary healthcare workers-accredited social health activists who motivate the eligible population in the community for screening. 


\section{Selection of participants}

The study participants were selected using a convenient sampling method. People were made aware of the importance of screening and about the diseases for which they are being screened. People who agreed to screening were included in the study.

All people in the age group 30-65 years and those having a history of tobacco use in other age groups (as per the operational guidelines) [25] and residing in urban slums were included in the study.

A total of 2043 urban slum dwellers were included in the study. The study was conducted from December 2016 to June 2019.

\section{Operational definitions}

Slum dweller-a person living in an urban slum for 6 months or more [26].

Smoker-a consumer of cigarettes, bidis, hookah, hand-rolled cigarettes, pipes, cigars/cheroots/cigarillos and any other reported smoked tobacco products [4].

SLT user-consumption included khaini, gutkha, betel quid (with tobacco) and any other reported SLT products which are edible, applied orally or inhaled; non-tobacco areca nut-based products were also included under this category [4].

Current tobacco user-any person giving a history of tobacco use on the day of the interview was termed as a current tobacco user [4].

Former/past tobacco user-any person who stated to have quit tobacco use on the day of the interview was termed as former/past tobacco use [4].

\section{Data collection and processing}

Following written informed consent, a detailed history of tobacco use was elicited from all the study participants.

The participants were interviewed using the pre-designed online clinical patient record form wherein their demographic details and tobacco use history, if present (current status, type of tobacco product used, amount, duration and frequency of tobacco use), were recorded. To ensure accurate data entry and to avoid missing data, regular monitoring of data was done utilising inbuilt data checks in the online software.

A number of potential sources of bias were noted and appropriate measures were undertaken to address these. Tobacco consumption is still quite a taboo among women who are thus not always comfortable revealing such information. Owing to a majority of females, and thus the impending information bias, a conducive, comfortable environment was developed for the participant by first building a rapport, followed by gradual probing regarding their tobacco history. Two different investigators elicited information by framing questions in slightly different ways to overcome recall bias.

\section{Statistical methods used}

The collected data were entered into an excel file, and analysed using the Statistical Package for the Social Sciences version 21, and OpenEpi open-source software. For categorical data, the percentage of different parameters was calculated and for quantitative data, descriptive statistics were calculated (mean, standard deviation and range). Chi-square or Fisher's exact test was used to find an association between two categorical variables. To find the strength of association between tobacco use and the socio-demographic factors, univariate and multivariable binary logistic regression was used. Socio-demographic variables which were considered for analysis were dichotomised. For example, the education variable was split into two: literate (those with some formal education including those who could only read and write) and illiterate (those who had not received any formal education and could not read and write). For income stratification, the BG Prasad classification [27] was used. The higher side income of the middle class was taken as the cut-off for dichotomisation of the variable. A statistical significance was established at a $p$-value $<0.05$. 


\section{Ethical guidelines followed by the investigators}

The study was approved by the institutional ethical committee (approval number: ICPO/IEC/2014). Written informed consent was taken from all participants who were involved in the study.

\section{Results}

The data obtained from 2043 participants were analysed.

\section{Socio-demographic details}

All the socio-demographic details of the study participants are given in Table 1.

The participants were aged between 16 and 85 years [average age $=36.3( \pm 10.9)$ years]. The majority were married $(92.5 \%)$, homemakers (majority female population)/students (64.6\%) and illiterate (36.2\%), with a monthly per capita income of $\leq 3,500$ of Indian rupees among the majority of the study participants (Table 1).

\section{Prevalence and pattern of tobacco use}

Among the 2,043 urban slum dwellers, 308 (15.06\%) individuals were current tobacco users (166 males and 142 females) and 64 (3.1\%) individuals were former tobacco users, while 1,671 (81.8\%) individuals never consumed tobacco (Figure 1). Majority of the current tobacco users consumed SLT (68.8\%), followed by tobacco smoking (16.9\%), while $14.3 \%$ of individuals consumed both (dual users). Among both genders, females showed a similar pattern of consumption; however, among males, SLT use was predominant, followed by dual tobacco use and smoked tobacco use.

The pattern of current tobacco use varied with regard to different socio-demographic factors; a significant association was found between the type of tobacco use (smoked, smokeless or both) with age, gender and education (Table 2).

\section{Types of tobacco products consumption-current tobacco users}

As summarised in Table 3, the most common type of tobacco products used among the current tobacco users were khaini (28.5\%), gutkha (23.0\%), bidi (22.8\%) and gulmanjan/gul (21.1\%). Bidi was the preferred form of smoked tobacco among both genders. However, a gender variation was noted in the consumption of SLT products, with khaini (42.1\%) and gutkha (32.5\%) use being most common among males, while gulmanjan/gul (36.1\%) was the most widely consumed product by females, followed by non-tobacco, areca nut-based products (betel quid pan masala and supari) (19.1\%). The type of tobacco products used was strongly associated with gender (Table 3).

\section{Determinants of tobacco use for current and past tobacco users}

Table 4 shows age greater than 45 years, being male, having education till middle school or below (includes illiterates) and being single/ widowed/separated/divorced as significant determinants for current tobacco use. The odds of current tobacco use were 3.85 among males as compared to females, 1.49 among individuals aged 45 years and above as compared to those younger than 45 years, 1.58 among those who were illiterate or had education till middle school and 2.11 among those who were single/separated/divorced/widowed as compared to married individuals. The main determinant for former tobacco users was being male [odds ratio $(\mathrm{OR})=3.45, p=0.00$ ], as the other sociodemographic factors were not found to affect former tobacco use. 
Table 1. Socio-demographic profile of the urban slum dwellers.

\begin{tabular}{|c|c|c|c|c|c|c|c|}
\hline \multirow{2}{*}{\multicolumn{2}{|c|}{ Demographic characteristic }} & \multicolumn{2}{|c|}{ Males $(n=602)$} & \multicolumn{2}{|c|}{ Females $(n=1,441)$} & \multicolumn{2}{|c|}{ Total $(n=2,043)$} \\
\hline & & $n$ & $\%$ & $n$ & $\%$ & $N$ & $\%$ \\
\hline \multirow[t]{7}{*}{ Age (in years) } & $15-24$ & 60 & 2.9 & 149 & 7.3 & 209 & 10.2 \\
\hline & $25-34$ & 191 & 9.3 & 543 & 26.6 & 734 & 35.9 \\
\hline & $35-44$ & 200 & 9.8 & 461 & 22.6 & 661 & 32.3 \\
\hline & $45-54$ & 98 & 4.8 & 207 & 10.1 & 305 & 14.9 \\
\hline & $55-64$ & 44 & 2.1 & 66 & 3.2 & 110 & 5.3 \\
\hline & $65-74$ & 7 & 0.3 & 12 & 0.6 & 19 & 0.9 \\
\hline & $\geq 75$ & 2 & 0.1 & 3 & 0.1 & 5 & 0.2 \\
\hline \multirow[t]{4}{*}{ Marital status } & Married & 541 & 26.5 & 1350 & 66.1 & 1891 & 92.5 \\
\hline & Divorced & 1 & 0.0 & 5 & 0.2 & 6 & 0.3 \\
\hline & Single & 42 & 2.1 & 19 & 0.9 & 61 & 3.0 \\
\hline & Widowed & 18 & 0.9 & 67 & 3.3 & 85 & 4.2 \\
\hline \multirow{5}{*}{ Occupation } & Clerical and support work, services and sales work & 17 & 2.8 & 6 & 0.4 & 23 & 1.1 \\
\hline & $\begin{array}{l}\text { Skilled workers and shop and market sales workers, skilled } \\
\text { agricultural and fishery workers, business including retailers }\end{array}$ & 50 & 8.2 & 60 & 4.1 & 110 & 5.3 \\
\hline & Elementary occupation & 239 & 39.6 & 236 & 16.3 & 475 & 23.2 \\
\hline & $\begin{array}{l}\text { Unemployed, retired, widowed, chronically ill, permanently } \\
\text { disabled }\end{array}$ & 104 & 17.2 & 10 & 0.6 & 114 & 5.5 \\
\hline & Student, homemaker & 192 & 31.8 & 1129 & 78.2 & 1321 & 64.6 \\
\hline \multirow[t]{7}{*}{ Education } & College and above & 47 & 2.3 & 74 & 3.6 & 121 & 5.9 \\
\hline & Intermediate & 83 & 4.1 & 142 & 6.9 & 225 & 11 \\
\hline & High School & 120 & 5.9 & 172 & 8.4 & 292 & 14.3 \\
\hline & Middle & 85 & 4.2 & 241 & 11.8 & 326 & 15.9 \\
\hline & Primary & 76 & 3.7 & 182 & 8.9 & 258 & 12.6 \\
\hline & Others/read and write & 32 & 1.6 & 50 & 2.5 & 82 & 4 \\
\hline & Illiterate & 159 & 7.8 & 580 & 28.4 & 739 & 36.2 \\
\hline \multirow[t]{3}{*}{ Religion } & Christian & 1 & 0.01 & 3 & 0.1 & 4 & 0.2 \\
\hline & Hindu & 547 & 26.8 & 1305 & 63.9 & 1854 & 90.7 \\
\hline & Muslim & 54 & 2.6 & 133 & 6.5 & 187 & 9.1 \\
\hline \multirow{5}{*}{$\begin{array}{l}\text { Monthly per capita } \\
\text { income (in Indian } \\
\text { rupees) }\end{array}$} & $<1,051$ & 40 & 2.0 & 67 & 3.3 & 107 & 5.2 \\
\hline & $1,051-2,101$ & 244 & 11.9 & 502 & 24.5 & 746 & 36.5 \\
\hline & $2,102-3,503$ & 184 & 9 & 530 & 26 & 715 & 35 \\
\hline & $3504-7007$ & 108 & 5.3 & 287 & 14 & 396 & 19.4 \\
\hline & $>7,008$ & 26 & 1.3 & 55 & 2.7 & 81 & 4 \\
\hline
\end{tabular}

aBG Prasad classification 2019 [27] 


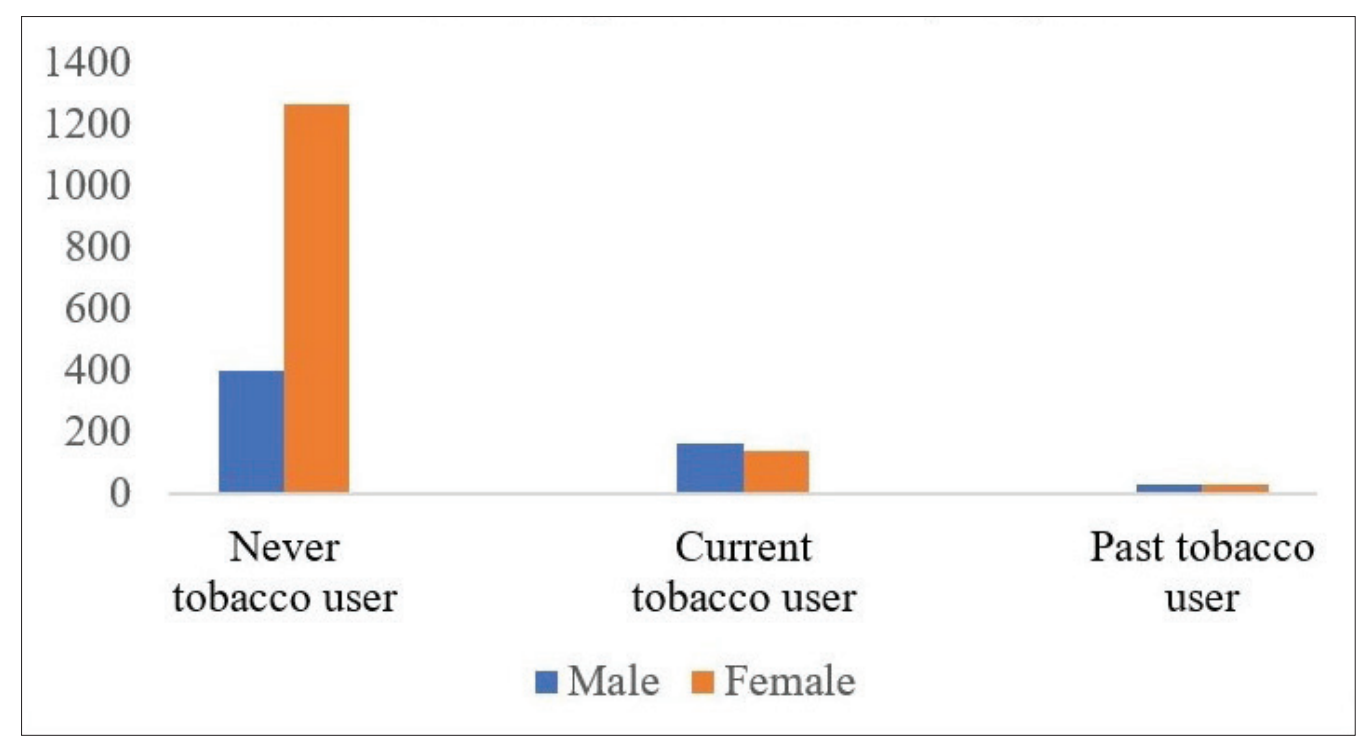

Figure 1. Tobacco use among male and female participants $(n=2043)$.

Table 2. Pattern of current tobacco use and its association with socio-demographic factors.

\begin{tabular}{|c|c|c|c|c|c|}
\hline Demographic characteristic & $\begin{array}{c}\text { Smoking } \\
(n=52,16.9 \%)\end{array}$ & $\begin{array}{c}\text { SLT } \\
(n=212,68.8 \%)\end{array}$ & $\begin{array}{l}\text { Dual tobacco use } \\
(n=44,14.3 \%)\end{array}$ & $\begin{array}{c}\text { Total } \\
(n=308,15.0 \%)\end{array}$ & $\begin{array}{c}\text { Chi-square test } \\
\text { ( } p \text { value) }\end{array}$ \\
\hline \multicolumn{6}{|l|}{ Age (in years) } \\
\hline Less than 45 & $29(9.4)$ & $157(51)$ & $27(8.8)$ & $213(69.2)$ & \multirow[t]{2}{*}{$8.01(p=0.02)$} \\
\hline Greater than or equal to 45 & $23(7.5)$ & $55(17.9)$ & $17(5.5)$ & $95(30.8)$ & \\
\hline \multicolumn{6}{|l|}{ Gender } \\
\hline Female & $22(7.1)$ & $110(35.7)$ & $10(3.2)$ & $142(46.1)$ & \multirow[t]{2}{*}{$12.83(p=0.00)^{\mathrm{a}}$} \\
\hline Male & $30(9.7)$ & $102(33.1)$ & $34(11)$ & $166(53.9)$ & \\
\hline \multicolumn{6}{|l|}{ Per capita monthly income (in Indian Rupees) } \\
\hline$>3,501$ & $15(4.9)$ & $40(13)$ & $11(3.6)$ & $66(21.4)$ & \multirow[t]{2}{*}{$2.86(p=0.24)$} \\
\hline Less than or equal to 3,500 & $37(12)$ & $172(55.8)$ & $33(10.7)$ & $242(78.6)$ & \\
\hline \multicolumn{6}{|l|}{ Education } \\
\hline Illiterate & $34(11)$ & $82(26.6)$ & $13(14.2)$ & $129(41.9)$ & \multirow[t]{2}{*}{$15.45(p=0.00)^{\mathrm{a}}$} \\
\hline Literate & $18(5.8)$ & $130(42.2)$ & $31(10.1)$ & $179(58.1)$ & \\
\hline \multicolumn{6}{|l|}{ Marital status } \\
\hline Married & $41(13.3)$ & $188(61)$ & $36(11.7)$ & $265(86)$ & \multirow[t]{2}{*}{$4.12(p=0.13)$} \\
\hline Others (single/divorced/separated/widowed) & $11(3.6)$ & $24(7.8)$ & $8(2.6)$ & $43(14)$ & \\
\hline
\end{tabular}

asignificant at $p<0.05$. 
Table 3. Prevalence of the various tobacco products used among current tobacco users.

\begin{tabular}{|c|c|c|c|c|c|c|c|}
\hline \multirow{2}{*}{ Tobacco product } & \multicolumn{2}{|c|}{ Males $(n=166)$} & \multicolumn{2}{|c|}{ Females $(n=142)$} & \multicolumn{2}{|c|}{ Total $(n=308)$} & \multirow{2}{*}{$p$-value } \\
\hline & $N$ & $\%$ & $n$ & $\%$ & $N$ & $\%$ & \\
\hline \multicolumn{8}{|l|}{ Smoked tobacco } \\
\hline Bidi & 44 & 26.5 & 26 & 18.44 & 70 & 22.80 & \multirow[t]{2}{*}{$p=0.28$} \\
\hline Cigarette & 18 & 10.8 & 5 & 3.55 & 23 & 7.49 & \\
\hline Others & 3 & 1.8 & 3 & 1.42 & 6 & 1.63 & \\
\hline \multicolumn{8}{|l|}{ SLT } \\
\hline Khaini & 70 & 42.1 & 18 & 12.7 & 88 & 28.5 & \\
\hline Gutkha & 54 & 32.5 & 17 & 12.0 & 71 & 23.0 & $x^{2}=76.94$ \\
\hline $\begin{array}{l}\text { Betel quid (with tobacco) and other regional/ } \\
\text { local tobacco preparations (gudhaku) }\end{array}$ & 28 & 16.8 & 25 & 17.7 & 53 & 17.2 & \multirow[t]{3}{*}{$p=<0.00001^{a}$} \\
\hline $\begin{array}{l}\text { Non-tobacco areca nut-based products (betel } \\
\text { quid without tobacco, pan masala, supari) }\end{array}$ & 9 & 5.5 & 27 & 19.1 & 36 & 11.7 & \\
\hline Gulmanjan/Gul & 14 & 8.4 & 51 & 36.1 & 65 & 21.1 & \\
\hline
\end{tabular}

asignificant at $p<0.05$

Table 4. Socio-demographic determinants of current and past tobacco use among urban slum participants ${ }^{\mathrm{a}}$.

\begin{tabular}{|c|c|c|c|c|}
\hline Demographic characteristic & $\begin{array}{l}\text { Current tobacco use }{ }^{b-} \\
\text { crude OR ( } p \text { value) }\end{array}$ & $\begin{array}{l}\text { Current tobacco use }{ }^{b} \\
\text { adjusted OR ( } p \text { value) }\end{array}$ & $\begin{array}{c}\text { Past tobacco use }{ }^{b} \text { crude } \\
\text { OR ( } p \text { value) }\end{array}$ & $\begin{array}{l}\text { Past tobacco use } \\
\text { adjusted OR ( } p \text { value) }\end{array}$ \\
\hline \multicolumn{5}{|l|}{ Age } \\
\hline Less than 45 & 1 & 1 & 1 & 1 \\
\hline Greater than or equal to 45 & $1.83(1.40-2.40) p=0.00^{c}$ & $1.49(1.12-1.99) p=0.01^{c}$ & $1.49(0.84-2.62) p=0.17$ & $1.24(0.69-2.23) p=0.48$ \\
\hline \multicolumn{5}{|l|}{ Gender } \\
\hline Female & 1 & 1 & 1 & 1 \\
\hline Male & $3.68(2.86-4.73) p=0.00^{c}$ & $3.85(2.97-4.99) p=0.00^{c}$ & $3.35(2.03-5.54) p=0.00^{c}$ & $3.45(2.06-5.76) p=0.00^{c}$ \\
\hline \multicolumn{5}{|c|}{ Per capita monthly income (in Indian Rupees) } \\
\hline$>3,001$ & 1 & 1 & 1 & 1 \\
\hline Less than or equal to 3,000 & $1.31(0.99-1.73) p=0.06^{c}$ & $1.02(0.75-1.39) p=0.91$ & $1.40(0.78-2.53) p=0.26$ & $1.24(0.65-2.38) p=0.52$ \\
\hline \multicolumn{5}{|l|}{ Education } \\
\hline High school and above & 1 & & 1 & 1 \\
\hline $\begin{array}{l}\text { Middle school and below } \\
\text { (includes illiterates) }\end{array}$ & $1.34(1.02-1.76) p=0.04^{c}$ & $1.58(1.17-2.13) p=0.003^{c}$ & $1.22(0.70-2.13) p=0.48$ & $1.41(0.78-2.54) p=0.26$ \\
\hline \multicolumn{5}{|l|}{ Marital status } \\
\hline Married & 1 & 1 & 1 & 1 \\
\hline Others & $2.52(1.73-3.69) p=0.00^{c}$ & $2.11(1.42-3.14) p=0.00^{c}$ & $2.22(1.03-4.79) p=0.04^{c}$ & $1.92(0.88-4.20) p=0.10$ \\
\hline
\end{tabular}

OR = odds ratio

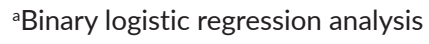

${ }^{\mathrm{b}}$ Reference group is never tobacco user

cSignificant at $p<0.05$ 


\section{Discussion}

\section{Socio-demographic profile}

Tobacco use was more prevalent among males than females, as seen in the current study and also reported by the GATS-2 (UP) [28] and few other studies conducted in the Indian urban slums [12, 15, 19, 21, 23]. This stark gender variation may be attributed to tobacco consumption being a societal taboo among females in India.

\section{Prevalence and pattern of tobacco use}

The prevalence of current tobacco use among the study participants belonging to the urban slums of Noida (UP), India, was $15 \%$. The same in GATS-2 for India [4] was $28.6 \%$ and $35.5 \%$ for UP [28]. The prevalence for current tobacco use was lower in the current study which may be due to a skewed sample with a greater number of females. The current tobacco use among males was $27.5 \%$ and among female was $9.8 \%$, which was found to be lower when compared to the same in the GATS-2 report [28].

In the current study, the majority consumed SLT (68.8\%), followed by smoked tobacco (16.9\%) and both (14.3\%). This is in line with the GATS-2 survey of UP [28]. Similar findings were noted in a study carried out among the urban slum dwellers of Bengaluru (Karnataka) [18]. However, in studies carried out in the urban slums of Shillong (Meghalaya) [23] and North 24 Parganas (West Bengal) [15], a high percentage of SLT users was followed by an almost similar percentage of smokers and dual users. On the contrary, a majority of dual tobacco users was followed by SLT users, and smokers in the urban slums of Bhopal (Madhya Pradesh) [19], whereas equal percentages of dual tobacco and SLT users, with a relatively lower percentage of smokers, were seen in the Shillong urban slums [22]. Overall, SLT use was more prevalent than smoked tobacco; hence, appropriate policy measures towards its control are essential.

\section{Types of tobacco products consumption: current tobacco users}

In our study, khaini (28.5\%) was the most common tobacco product consumed. This was followed by gutkha (23\%) consumption. The type of tobacco products consumed overall was similar to that consumed by rural residents of UP as per the GATS-2 for UP [28]. However, the choice of SLT product among the urban residents of UP was different, with gutkha (10.2\%) being the product of choice for consumption, followed by khaini (9.1\%) [28]. This is suggestive of the retention of the original tobacco consumption practice by the rural natives in spite of migrating to urban areas. Most males consumed khaini (42.1\%) and gutkha (32.5\%), while gul (36.1\%) use was most common among females in the present study.

As mentioned above, certain tobacco products have shown a much higher prevalence of consumption by females, such as gul, including in the current study (most commonly used tobacco product by them). Even the GATS-2 for UP [28] reported gul as the second most widely used tobacco product among women (rural and urban). Multiple studies have reported high consumption of gul among Indian females, such as those conducted in rural Patna [33], at a tertiary care centre in Delhi [34] and in an urban slum of Mumbai [17]. In a study conducted in Bangladesh, another country with indigenous gul use, almost twice the prevalence was reported among females (10\%) than males (5.3\%) [35]. Orodental pain secondary to dental caries, endodontic lesions or periodontal conditions, such as periodontitis or gingivitis, has been reported as the main reason for the initiation of gul, due to the acute analgesic effect of tobacco [36, 37]. Gul has also been shown to be highly addictive in nature [38], with a reported average frequency of use from 2 up to 50 times per day [17, 39, 40]. Hence, gender-targeted tobacco control advocacy, exclusively for female tobacco users, is the need of the hour.

\section{Determinants of tobacco use for current and past tobacco users}

Age, gender and education showed a significant association with the tobacco form used (smoked, SLT or both), in both the current study and that in the urban slum of Shillong [23]. GATS-2, India [4], also reported an increase in the overall tobacco prevalence with increasing age, low education levels and in males. 
Older age and males were significant determinants for tobacco use in our study as well as in the study conducted in the urban slums of Chennai [14], while illiteracy as a significant determinant of tobacco use was reported in the study conducted in Faridabad [13], in addition to ours.

A systematic review showed that SLT use was more common among the lower socio-economic group, less educated and older population [41].

Apart from tobacco-containing areca nut products, plain areca nut-based products (i.e. without tobacco), such as betel quid (without tobacco), pan masala, and supari, were also widely consumed (11.7\%) by the participants, especially females (second most widely consumed tobacco product type). The GATS-2 UP [28] also reported a high overall (rural and urban) prevalence of non-tobacco products (pan masala, 7\%; betel quid, 12.8\%; and areca nut 7.6\%). Significant consumption of pan masala was also observed in the urban slums of Shillong [23] and Bengaluru [18]. The chewing of areca nut is an ancient practice ingrained in the Indian culture [29]. Betel leaf and areca nut are an integral part of Hindu ceremonies and a source of livelihood for the many Indian states [30]. Its consumption is socially acceptable, including among both women and children [31]. However, areca nut has been classified as a group 1 carcinogen by the International Agency for Research on Cancer [32], thereby deeming the control and monitoring of its consumption as essential as tobacco.

The Government of India has actively proposed various tobacco control policies; however, their effective, complete implementation is the need of the hour. The patterns of tobacco consumption, across the various strata of the society, i.e. urban, rural and slums, should be continuously assessed, which will in turn help in developing effective, appropriate interventions for the same [42]. Sensitisation and encouraging healthcare providers regarding tobacco cessation assistance are needed [43]. The tobacco cessation programme may be collated with other existing healthcare programmes [42]. Also, education and awareness regarding the adverse health effects due to tobacco consumption need to be spread [43].

\section{Limitations of this study}

The study population may not be a true representation of the community due to the institutional clinic setting and convenience sampling.

However, the study provides important insights into the tobacco use habits of the urban slum dwellers who are usually migrants and are slowly growing in numbers due to the increase in urbanisation. A predominance of females in the study population not only provides essential information regarding their tobacco use patterns but also important cues about their health-seeking behaviour, by virtue of them attending our clinic for accessing breast and cervical cancer screening services.

\section{Conclusion}

The present study is the first to report the prevalence of tobacco use among the urban slum population of Noida (UP), India. SLT is the most widely consumed tobacco form, even in this population attending the clinic, thus reaffirming the importance of SLT control, compared to that of smoked tobacco, in our country. The study brings up the fact that the lower socio-economic group, less educated, males and the older population are more likely to consume tobacco in an urban slum. Although tobacco use is less prevalent among women, they do consume areca nut products and other forms of tobacco, such as 'gul', which they consider safe to use. Hence, the National Tobacco Control Programme may focus on these population groups to control tobacco use.

\section{Conflicts of interest}

The authors declare that they have no conflict of interests. 


\section{Funding}

This work was supported by the Indian Council of Medical Research [5/13/49/2014/NCD-III].

\section{Authors' contributions}

Conception or design of the work, acquisition, analysis and interpretation of data: STN, DNS, VK, AK and SS. Drafting the work or revising it critically for important intellectual content: STN, DNS, AK, RH and RM. Final approval of the version published: DNS and RM. Agreement to be accountable for all aspects of the work in ensuring that questions related to the accuracy or integrity of any part of the work are appropriately investigated and resolved: STN, DNS, VK, AK, SS, RH and RM.

\section{References}

1. Tobacco free initiative [https://www.who.int/tobacco/mpower/en/] Date accessed: 21/06/19

2. Noncommunicable diseases [https://www.who.int/news-room/fact-sheets/detail/noncommunicable-diseases] Date accessed: $07 / 06 / 20$

3. Smokeless tobacco and public health: a global perspective [https://cancercontrol.cancer.gov/brp/tcrb/smokeless-tobacco] Date accessed: $14 / 04 / 21$

4. Global adult tobacco survey 2, India 2016-17 [https://www.tiss.edu/view/6/mumbai-campus/school-of-health-systems-studies/ global-adult-tobacco-survey-2-india-2016-17/outcomespublications-3/] Date accessed: 14/04/21

5. Report of national cancer registry programme 2020 [https://www.ncdirindia.org/All_Reports/Report_2020/default.aspx] Date accessed: $13 / 04 / 21$

6. Gupta B and Johnson NW (2017) Oral cancer: Indian pandemic Br Dent J 222497 https://doi.org/10.1038/sj.bdj.2017.293 PMID: 28387269

7. Nolan L (2015) Slum Definitions in Urban India: implications for the measurement of health inequalities Popul Dev Rev 41 59-84 https:// doi.org/10.1111/j.1728-4457.2015.00026.x

8. Census 2001 India: office of the Registrar General \& Census Commissioner [https://censusindia.gov.in/Tables_Published/Admin_Units/ Admin_links/slumnote.html] Date accessed: 21/06/19

9. Population projections for India and states 2001-2026: report of the technical group on population projections constituted by the national commission on population [http://gujhealth.gov.in/basicstatastics/pdf/Proj ection_Report.pdf] Date accessed: 21/06/19

10. Uttar Pradesh slums census 2011 [https://www.census2011.co.in/data/slums/state/9-uttar-pradesh.html] Date accessed: 21/06/19

11. National family health survey, India [http://rchiips.org/nfhs/index.shtml] Date accessed: 21/06/19

12. Anand K, Shah B, and Yadav K, et al (2007) Are the urban poor vulnerable to non-communicable diseases? A survey of risk factors for non-communicable diseases in urban slums of Faridabad Natl Med J India 20 115-120 PMID: 17867614

13. Gupta V, Yadav K and Anand K (2010) Patterns of tobacco use across rural, urban, and urban-slum populations in a north Indian community Indian J Community Med 35 245-251 https://doi.org/10.4103/0970-0218.66877 PMID: 20922100 PMCID: 2940179

14. Chockalingam K, Vedhachalam C, Rangasamy S, Sekar G, Adinarayanan S, Swaminathan S, Menon PA (2013) Prevalence of tobacco use in urban, semi urban and rural areas in and around Chennai City, India PLoS One 8 e76005 https://doi.org/10.1371/journal.pone.0076005 PMID: 24098418 PMCID: 3788037 
15. Acharyya T, Kaur P and Murhekar MV (2014) Prevalence of behavioural risk factors, overweight and hypertension in the urban slums of North 24 Parganas District, West Bengal, India, 2010 Indian J Public Health 58 195-198 https://doi.org/10.4103/0019-557X.138632 PMID: 25116826

16. Mukherjee K (2015) Study on tobacco consumption patterns and its determinants in an urban slum in New Mumbai Int J Epidemiol Res 2 164-171

17. Nair S, Schensul JJ, and Begum S, et al (2015) Use of smokeless tobacco by Indian women aged 18-40 years during pregnancy and reproductive years PLoS One 10 e0119814 https://doi.org/10.1371/journal.pone.0119814

18. Hussain CA, Saba H, and Gopi A et al (2016) Tobacco prevalence and usage pattern among Bengaluru urban slum dwellers Int J Community Med Public Health 3 432-436 https://doi.org/10.18203/2394-6040.ijcmph20160426

19. Santha B, Saxena V, and Jain M, et al (2017) Oral sub mucous fibrosis and tobacco use among slum dwellers of Bhopal City, India Dentistry 7 1-4 https://doi.org/10.4172/2161-1122.1000455

20. Joy TM, Sreelakshmi M, and Nimitha P, et al (2017) Prevalence of tobacco use in an urban slum population in Kochi, Kerala Natl J Res Community Med 6 110-115

21. Sarkar BK, Shahab L, and Arora M, et al (2017) The social gradient in tobacco use does not generalize to low-income urban communities in India: findings from a census survey Nicotine Tob Res 19 1516-1520

22. Bhattacharyya H, Pala S, and Medhi GK, et al (2018) Tobacco: consumption pattern and risk factors in selected areas of Shillong, Meghalaya J Family Med Prim Care 7 1406-1410 https://doi.org/10.4103/jfmpc.jfmpc_140_18

23. Sarkar A, Roy D and Nongpiur A (2019) A population-based study on tobacco consumption in urban slums: its prevalence, pattern, and determinants J Family Med Prim Care 8 892-898 https://doi.org/10.4103/jfmpc.jfmpc_42_19 PMID: 31041220 PMCID: 6482753

24. Rooban T, Joshua E, and Rao U et al (2012) Prevalence and correlates of tobacco use among urban adult men in India: a comparison of slum dwellers vs non-slum dwellers Indian J Dent Res 23 31-38 https://doi.org/10.4103/0970-9290.99034 PMID: 22842246

25. Operational framework management of common cancers [http://cancerindia.org.in/wp-content/uploads/2017/11/Operational_ Framework_Management_of_Common_Cancers.pdf] Date accessed: 22/06/19

26. Khandker NN, Biswas T, and Khan ANS, et al (2017) Socio-demographic characteristics and tobacco use among the adults in urban slums of Dhaka, Bangladesh Tob Induc Dis 1526 https://doi.org/10.1186/s12971-017-0131-1 PMID: 28484362 PMCID: 5420145

27. Pandey VK, Aggarwal P and Kakkar R (2019) Modified BG prasad socio-economic classification Indian J Comm Health 31 123-125

28. Global adult tobacco survey factsheet Uttar Pradesh 2016-17 [https://tiss.edu/uploads/files/Uttar_Pradesh.pdf] Date accessed: $14 / 04 / 21$

29. Sinha DN, Gupta PC and Pednekar MS (2003) Tobacco Use in a rural area of Bihar, India Indian J Community Med 28 167-170

30. Radhika AG, Kaur J, and Sharma T, et al (2014) Pregnancy outcomes in smokeless tobacco users cohort study in a tertiary care hospital Open J Obstet Gynecol 4 371-378 https://doi.org/10.4236/ojog.2014.47055

31. Azam MN, Shahjahan M, and Yeasmin M, et al (2016) Prevalence of smokeless tobacco among low socioeconomic populations: a crosssectional analysis PLoS One 11 1-13 https://doi.org/10.1371/journal.pone.0156887

32. Ditre JW, Heckman BW, and Zale EL et al (2016) Acute analgesic effects of nicotine and tobacco in humans Pain 15 1373-1381 https:// doi.org/10.1097/j.pain.0000000000000572

33. Bhonsle RB, Murti PR and Gupta PC (1990) Tobacco habits in India Proceedings of an International Symposium, eds PC Gupta, JE Hamner III, and PR Murti (Bombay: Oxford University Press) pp 25-46 
34. Stanfill SB, Connolly GN, and Zhang L, et al (2010) Global surveillance of oral tobacco products: total nicotine, unionised nicotine and tobacco-specific N-nitrosamines Tob Control 20 1-10

35. Akhtar S and Khess CR (1994) Dependence on gul: an indigenous compound containing tobacco Indian J Psychiatry 36 96-97 PMID: 21743681 PMCID: 2972471

36. Huque R, Zaman M, and Huq S et al (2017) Smokeless tobacco and public health in Bangladesh Indian J Public Health 61 S18-S24 https://doi.org/10.4103/ijph.IJPH_233_17 PMID: 28928314 PMCID: 6349136

37. Thakur JS and Paika R (2018) Determinants of smokeless tobacco use in India Indian J Med Res 148 41-45 https://doi.org/10.4103/ijmr. IJMR_27_18 PMID: 30264753 PMCID: 6172920

38. Strickland SS (2002) Anthropological perspectives on use of the areca nut Addict Biol 7 85-97 https://doi.org/10.1080/13556210120091446 PMID: 11900627

39. Travasso C (2013) Betel quid chewing is responsible for half of oral cancer cases in India, finds study BMJ $347 \mathrm{f7536}$ https://doi. org/10.1136/bmj.f7536 PMID: 24343058

40. Gupta PC and Ray CS (2004) Epidemiology of betel quid usage Ann Acad Med Singapore 33 31-36 PMID: 15389304

41. IARC Working Group on the Evaluation of Carcinogenic Risks to Humans (2004) Betel-quid and areca-nut chewing and some areca-nut derived nitrosamines IARC Monogr Eval Carcinog Risks Hum 85 1-334

42. Mohan P, Lando HA and Panneer S (2018) Assessment of tobacco consumption and control in India Indian J Clin Med 9 1-8 https://doi. org/10.1177/1179916118759289

43. Mckay AJ, Patel RKK and Majeed A (2015) Strategies for tobacco control in India: a systematic review PLoS One 10 1-34 https://doi. org/10.1371/journal.pone.0122610 